\title{
Realias gyvenimo sąlygas atspindinčio perspektyviojo tyrimo PRISMA rezultatai
}

\author{
Deimantè Hoppenot \\ LSMU MA Pulmonologijos ir imunologijos klinika
}

Reikšminiai žodžiai: perspektyvusis tyrimas, kombinuotas gydymas, realios gyvenimo sąlygos, astmos kontrolè.

Santrauka. Straipsnyje pristatomi realias gyvenimo sąlygas atspindinčio perspektyviojo momentinio PRISMA tyrimo rezultatai.

Astma - plačiai pasaulyje paplitusi liga. Pasaulyje ja serga daugiau nei 300 milijonų ívairaus amžiaus žmonių [1]. Tarptautinėse astmos gydymo rekomendacijose $[1,2] \mathrm{nu}-$ rodoma, kad pagrindinis medikamentinio astmos gydymo tikslas - astmos kontrolè. Gydant siekiama valdyti astmos simptomus, užtikrinti normalią kasdienę paciento veiklą bei fizini aktyvumą, išlaikyti paciento kvèpavimo funkciją kuo artimesnę normaliai, apsaugoti nuo astmos paūmèjimų ir mirties nuo astmos bei išvengti nepageidaujamo vaistu poveikio. Astmos gydymo išlaidos priklauso nuo astmos kontrolès laipsnio ir nuo to, kaip sekasi išvengti astmos paūmèjimų. Remiantis GINA rekomendacijomis, astmos kontrolè esti trijų laipsnių: kontroliuojama, iš dalies kontroliuojama ir nekontroliuojama astma. Nuolatinè paciento būklès stebėsena reikalinga ịsitikinti, kad astmos kontrolè pasiekta ir išlaikoma mažiausiai 3 mènesius, prieš keičiant medikamentini gydymą [1].

Nepaisant naujų astmai gydyti sukurtų vaistų bei patvirtintų vaistų derinių, prasta astmos kontrole - gana dažnas reiškinys. Europos Sąjungos kvépavimo sistemos sveikatos tyrimo ECRHS II, vykdyto 11-oje Europos Sąjungos šalių, rezultatai rodo, kad tik 32 proc. tyrime dalyvavusių pacientu astma buvo kontroliuojama. $2006 \mathrm{~m}$. perspektyviajame tyrime, vykdytame penkiose Europos šalyse, nustatyta, jog astma nevisiškai kontroliuota 50,4 proc. tiriamųjų [3], o pakartojus ši tyrimą tose pačiose šalyse 2008 m. paaiškejjo, jog nepakankamai kontroliuojamos astmos atvejų netgi šiek tiek padaugèjo - iki 56,6 proc. [4]. Nors įvairių tyrimų duomenys skelbia, kad astma nepakankamai kontroliuojama apie pusei ligonių, sunku atlikti astmos tyrimų analizę bei palyginti rezultatus, nes tyrimuose kontroliuojama astma apibréžiama skirtingai, nevienodi ir tyrimo metodai.

Atsižvelgiant i šias priežastis, ypač atkreipiant dèmesi i tai, kad ankstesniuose tyrimuose buvo renkami skirtingi duomenys, o astmos kontrolei nustatyti taikyti skirtingi tyrimai, buvo sukurta PRISMA studija - realias gyvenimo sąlygas atspindintis perspektyvusis momentinès fazès tyrimas, kuriuo siekta nustatyti Italijos astma sergančių suaugusiųjų astmos kontrolès laipsnị. Kiti PRISMA tyrimo tikslai: išsiaiškinti blogos astmos kontrolès priežastis, palyginti gyvenimo kokybę bei finansines gydymo išlaidas skirtingai kontroliuojamos astmos grupèse [6].

\section{METODAI IR TIRIAMŲJŲ KONTINGENTAS}

PRISMA tyrimas - momentinès ir 12 mènesių perspektyviosios fazių tyrimas. Tyrimas sukurtas taip, kad būtu galima įvertinti astmos kontrolę realiomis gyvenimo sąlygomis bei stebèti, astmos kontrolès kaitą per vienerius metus. Tyrimu siekta nustatyti iš dalies kontroliuojamos ir nekontroliuojamos astmos paplitimą Italijoje [6].

I tyrimą įtraukti rūkantys ir nerūkantys astma sergantys suaugusieji, kuriems astmos diagnozè nustatyta ne anksčiau kaip prieš 6 mènesius. Pacientai, dalyvaujantys kituose klinikiniuose tyrimuose ar juose dalyvavę 12 savaičiu laikotarpiu iki PRISMA tyrimo, sergantys sunkiomis gretutinėmis ligomis bei nėščios moterys tyrime negalejo dalyvauti. Pacientai i tyrimą buvo įtraukiami nuo 2009 sausio iki 2009 metų spalio ménesio 56 Italijos plaučių ligu gydymo centruose [6].

\section{REZULTATAI}

I tyrimą įtraukti 2853 pacientai iš 56 Italijos plaučių ligu gydymo centrų, iš jų 64,4 proc. astma buvo kontroliuojama, 15,8 proc. - iš dalies kontroliuojama ir 19,8 proc. nekontroliuojama. Pagrindinès priežastys, lèmusios blogą astmos kontrolę buvo šios: netinkamas vaistų vartojimas 


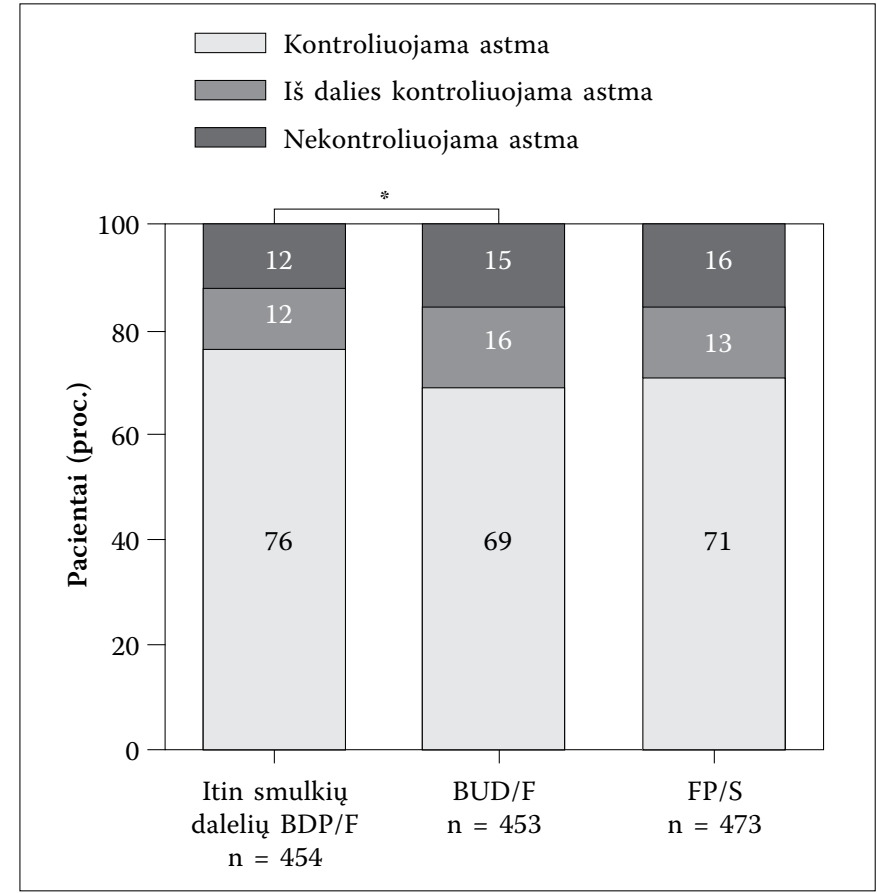

1 pav. Procentinis pacientu, gydytu sudetiniais IGK/IVBA vaistais, pasiskirstymas kontroliuojamos, iš dalies kontroliuojamos ir nekontroliuojamos astmos grupèse

* Koreguotas pagal Bonferroni $\mathrm{p}=0,0320$, lyginant su BUD/F (kontroliuojama astma sergantys pacientai, lyginant su sergančiais iš dalies kontroliuojama ir nekontroliuojama kartu).

$\mathrm{BDP} / \mathrm{F}$ - beklometazonas/formoterolis; BUD/F - budezonidas/formoterolis; $\mathrm{FP} / \mathrm{S}$ - flutikazonas/salmeterolis.

(43,3 proc.), astmą sukeliančių veiksnių ekspozicija (29 proc.), nesèkmingas paciento ir gydytojo bendravimas (21,2 proc.), paskirtas netinkamas gydymas (19,9 proc.). Rūkančiu buvo daugiau nekontroliuojamos (21,2 proc.) ir iš dalies kontroliuojamos (17,1 proc.) astmos grupèse. Aukštesnị išsimokslinimą turinčių ligonių grupèje gerai astma buvo kontroliuojama didesnei daliai tiriamųjų nei turinčiųjų žemesni išsimokslinimą. Nekontroliuojama ir iš dalies kontroliuojama astma sergantiems pacientams dažniau nustatytos šios gretutinès patologijos: gastroezofaginio refliukso liga (GERL), sinusitas, kvejpavimo taku infekcijos, psichologiniai sutrikimai. Nekontroliuojama astma dažniau nustatyta ilgiau ją sergantiems tiriamiesiems nei kontroliuojama ar iš dalies kontroliuojama [6].

Inhaliuojamojo gliukokortikoido ir ilgo veikimo beta 2 receptorių agonisto (IGK/IVBA) sudètiniai vaistai buvo dažniausiai vartojami vaistai astmai gydyti (56 proc.). Inhaliuojamuosius gliukokortikoidus (IGK) vartojo 11,5 proc., o leukotrienų receptorių antagonistus (LTRA) 24,3 proc. pacientų. Ilgai veikiančiais beta 2 receptorių agonistais (IVBA) gydyti 22,2 proc. tyrime dalyvavusiu pacientu.

Sudètinis IGK/IVBA vaistas mažiausiai 4 savaites buvo skiriamas 48,4 proc. tyrime dalyvavusiuc pacientuc ( $\mathrm{n}=$ 1380), iš jų itin smulkių dalelių beklometazonas/formoterolis (BDP/F) - 454 pacientams (32,9 proc.), budezonidas/ formoterolis (BUD/F) - 453 pacientams (32,8 proc.) bei

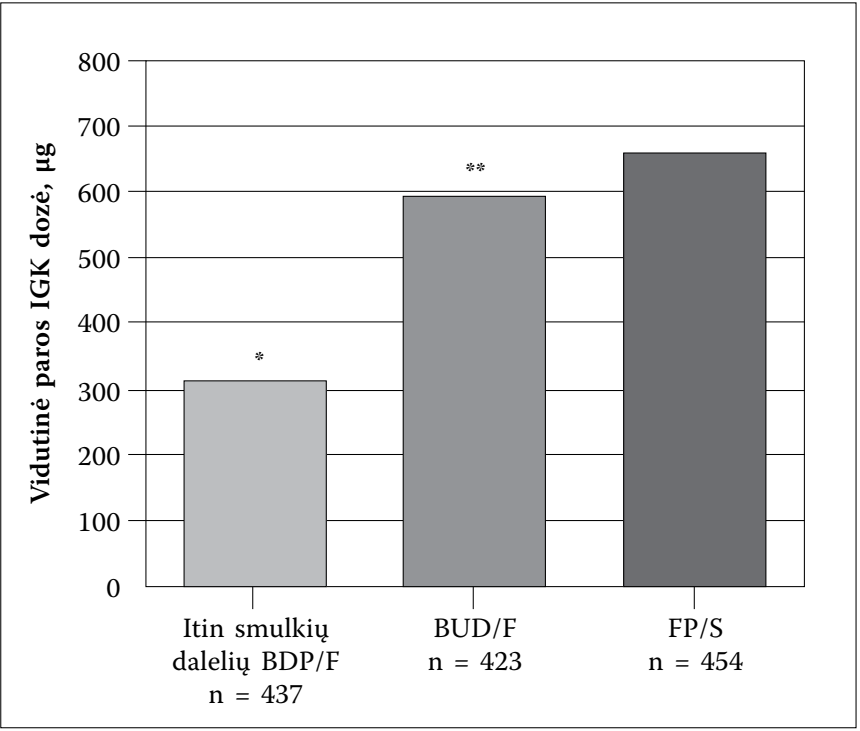

2 pav. Vidutinè IGK dozè gydant sudètiniais IGK/IVBA vaistais

* Pagal Bonferroni koreguotas $\mathrm{p}<0,0001$, lyginant su BUD/F ir FP/S. * Pagal Bonferroni koreguotas $\mathrm{p}<0,0001 \mathrm{vs}$ FP/S

$\mathrm{BDP} / \mathrm{F}$ - beklometazonas/formoterolis; BUD/F - budezonidas/formoterolis $\mathrm{FP} / \mathrm{S}$ - flutikazonas/salmeterolis.

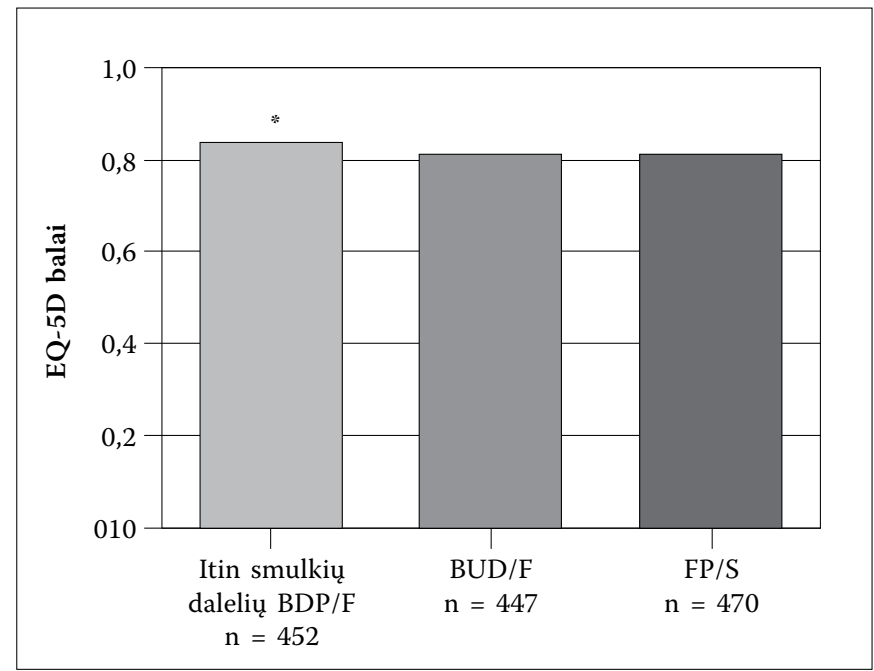

3 pav. EQ-5D sveikatos būklès rezultatai (nuo 0 iki 1) gydant sudètiniais IGK/IVBA vaistais

* Pagal Bonferroni koreguotas $\mathrm{p}=0,018$ lyginant su FP/S

$\mathrm{BDP} / \mathrm{F}$ - beklometazonas/formoterolis; BUD/F - budezonidas/formoterolis;

FP/S - flutikazonas/salmeterolis; EQ-5D - Europos gyvenimo kokybés klausimynas.

flutikazonas/salmeterolis - 473 pacientams (34,3 proc.).

Iš pacientų, gydytų IGK/IVBA, astma buvo kontroliuojama 72,1 proc., iš dalies kontroliuojama - 13,7 proc., o nekontroliuojama - 14,2 proc. Pacientų, gydytų itin smulkių dalelių BDP/S, grupeje kontroliuojamos astmos atveju buvo daugiau nei vartojusiųjų BUD/F. Šansų, kad astma bus kontroliuojama, santykis gydant itin smulkių dalelių $\mathrm{BDP} / \mathrm{F}$ buvo didesnis nei gydant kitais dviem vaistu deriniais $(\mathrm{p}=0,012)$.

Gydant itin smulkių dalelių BDP/F sudètiniu vaistu vidutinè IGK paros dozè buvo mažesnè nei BUD/F ir FP/S grupèse, o gyvenimo kokybė geresnè [6]. 


\section{REZULTATŲ APTARIMAS}

PRISMA tyrimo rezultatai patvirtino kito tyrimo, Italijoje vykdyto 2005-2006 metais, rezultatus: 64,7 proc. pacientú astmos kontrolès testas buvo 20 baluc ir daugiau [8]. Pagrindinès priežastys, lèmusios nepakankamą astmos simptomų kontrolę PRISMA tyrime, buvo netinkamas vaistu vartojimas, astmą skatinančių veiksnių ekspozicija, paskirtas netinkamas medikamentinis astmos gydymas (pastarasis < 20 proc.).

Šiame tyrime dalyvavo didelis skaičius rūkančių ir nerūkančių astma sergančių pacientų. Tyrimo duomenys rodo, kad rūkymas yra reikšmingas blogos astmos kontrolès rizikos veiksnys.

Gretutinès ligos (rinosinusitas, GERL, kvėpavimo taku infekcijos, psichologiniai veiksniai) taip pat turi neigiamos itakos astmos kontrolei, todèl norint pasiekti ir kuo ilgiau išlaikyti astmos simptomų kontrolę būtina jas gydyti.

PRISMA tyrimu tvirtai įrodyta, kad pacientai, kurių astma nekontroliuojama ar iš dalies kontroliuojama, dažniau lankosi skubiosios pagalbos skyriuje ir yra dažniau hospitalizuojami. Šiu pacientų gyvenimo kokybė yra blogesnè nei tų, kuriems astma kontroliuojama gerai.

PRISMA tyrimas patvirtino, kad astma geriau kontroliuojama gydant inhaliuojamojo gliukokortikoido ir ilgo veikimo beta 2 receptorių agonisto sudètiniu vaistu, beje, šis derinys dažniausiai vartotas astmai gydyti PRISMA tyrime. Šio tyrimo duomenys sutampa su anksčiau vykdytų klinikinių tyrimų išvadomis, kad IGK/IVBA sudètinis vaistas veiksmingiausias gydant astmą [6, 7-9]. Ištyrus tris sudètinius IGK/IVBA vaistus nustatyta, kad geresniu astmos kontrolès bei gyvenimo kokybès rezultatų pasiekiama gydant itin smulkių dalelių BDP/F. 2008 metais atliktame dideliame atsitiktinių imčių kontroliuojamame tyrime itin smulkių dalelių BDP/F lygintas su didelių dalelių BDP ir dideliu dalelių formoteroliu. Geresnè astmos kontrolè itin smulkių dalelių BDP/F pacientų grupejje pasiekta, manoma, dèl to, jog šio vaisto itin smulkių dalelių formulè lemia tolygų ir gerą vaistų pasiskirstymą plaučiuose [10].

Vartojant itin smulkių dalelių BDP/F, kitaip nei didelių daleliu BUD/F bei FP/S, abu vaistai efektyviai pasiekia tiek stambiuosius bronchus, tiek smulkiausias periferines bronchioles. Taip užtikrinamas uždegimo bei bronchų obstrukcijos gydymas visame bronchų medyje, kas lemia geresnį vaisto klinikini poveikị.

I PRISMA tyrimą buvo ịtrauktas nemažas skaičius astma sergančių rūkančių pacientų. Paprastai šie pacientai $\mathfrak{i}$ kvėpavimo ligų tyrimus neįtraukiami. Yra žinoma, kad rūkančių astmos ligonių atsakas ì gydymą IGK yra blogesni [12], nes IGK netinkamai pasiskirsto plaučiuose dèl padidejusio kvėpavimo taku pasipriešinimo. Remiantis PRISMA duomenimis, atrodo, jog iš itin smulkių dalelių sudarytiems inhaliuojamiesiems vaistams kvėpavimo taku pasipriešinimas turi mažai įtakos [11]. Manoma, kad ypač gerų rezultatų gydant astmą itin smulkių dalelių inhaliuojamaisiais vaistais galètų pasiekti astma sergantys ligoniai, kurie rūko.

Apibendrinant PRISMA tyrimo rezultatus, galima teigti, kad astma gali būti kontroliuojama didžiajai daliai pacientų, o kontroliuojama astma lemia geresnę gyvenimo kokybę bei mažesnes sveikatos priežiūros sistemos išlaidas. Dažniausiai astmai gydyti skiriamas IGK/IVBA sudètinis vaistas. Itin smulkių dalelių $\mathrm{BDP} / \mathrm{F}$ padeda geriau kontroliuoti astmą bei pagerinti gyvenimo kokybę vartojant mažesnę vaisto dozę nei gydant kitais IGK/IVBA sudètiniais vaistais.

\section{REAL-LIFE PROSPECTIVE STUDY PRISMA RESULTS}

\section{DEIMANTE HOPPENOT \\ DEPARTMENT OF PULMONOLOGY AND IMMUNOLOGY LITHUANIAN UNIVERSITY OF HEALTH SCIENCES}

Keywords: prospective study, combination therapy, real-life study, asthma control. Summary. This paper presents about real-life prospective study PRISMA, crosssectional phase results.

\section{LITERATŨRA}

1. Global Initiative for Asthma (GINA). Global strategy for asthma management and prevention. revised 2009. Available from:http://www.ginasthma.org.

2. National Heart Lung and Blood Institute. Global Initiative for Asthma. Global strategy for asthma management and prevention. NHLBI/WHO workshop report. Bethesda (MD): National Institutes of Health; 2006. National Heart Lung and Blood Institute publication no. 02-3659.

3. Demoly P, Paggiaro P, Plaza V, et al. Prevalence of asthma control among adults in France, Germany, Italy, Spain and the UK. Eur Respir Rev 2009; 18(112): 105e12.

4. Demoly P, Gueron B, Annunziata K, et al. Update on asthma control in five European countries: results of a 2008 survey. Eur Respir Rev 2010; 19(116): $150 \mathrm{e} 7$.

5. Allegra L., Cremonesi G, Girbino G, et al. Real-life prospective study on asthma control in Italy: Cross-sectional phase results, Respiratory Medicine (2011), doi: 10.1016/j.rmed. 2011.10.001

6. O'Connor RD, Carranza Rosenzweig JR, Stanford RH, et al. Asthma-related exacerbations, therapy switching, and therapy discontinuation: a comparison of 3 commonly used controller regimens. Ann Allergy Asthma Immunol 2005; 95: 535e40.

7. O'Connor RD, Gilmore AS, Manjunath R, Stanford RH, Legorreta AP, Jhingran PM. Comparing outcomes in patients with persistent asthma: a registry of two therapeutic alternatives. Curr Med Res Opin 2006; 22: 453e61.

8. Bettoncelli G, Magnoni MS, Fassari C, et al. Studio P.A.C.I.S. (Point out Asthma Control Italian Survey). Il controllo dell'asma in Italia misurato con ACT (Asthma Control Test). Societa` Italiana di Medicina Generale 2006; 6: $10 \mathrm{e}$.

9. Trautmann M, Banik N, Tews JT, JoØrres RA, Novak D. Efficacy of the combinations of fluticasone propionate and salmeterol in patients with moderate persistent asthma within a real-life setting. Eur J Respir Med June 2007; 12: $255 \mathrm{e} 63$.

10. Huchon G, Magnussen H, Chuchalin A, Dymek L, Gonod FB, Bousquet J. Lung function and asthma control with beclomethasone and formoterol in a single inhaler. Respir Med 2009; 103 (1): 41e9

11. Invernizzi G, Ruprecht A, De Marco C, Mazza R, Nicolini G, Boffi R. Inhaled steroid/tobacco smoke particle interactions: a new light on steroid resistance. Respir Res Jun 11 2009; 10: 48.

12. Thomson NC, Chaudhuri R. Asthma in smokers: challenges and opportunities. Curr Opin Pulm Med Jan 2009; 15 (1): 39e45. Review. 